Akadémiai Kiadó - Springer-Verlag

\title{
ERRATUM
}

\section{PRINCIPAL STRUCTURE OF SUBMODULAR SYSTEMS AND HITCHCOCK-TYPE INDEPENDENT FLOWS}

\section{SATORU IWATA}

Received January 2, 1996

A recent paper of mine [1] contains an error, which is not critical to the main result but still may confuse the readers. I would like to apologize this sincerely and show how to fix it.

In Section 4.3, Corollary 4.8 and its proof should be replaced as follows.

Corollary 4.8. For any $X_{1}, X_{2} \subseteq S$ and $y \geq 0$ it holds that

$$
f\left(X_{1}\right)+f_{\langle y\rangle}\left(X_{2}\right) \geq f\left(X_{1} \cap X_{2}\right)+f_{\langle y\rangle}\left(X_{1} \cup X_{2}\right) \text {. }
$$

Proof. It follows from Lemma 4.7 and the monotonicity of $\sigma$ that

$$
\sigma^{\#}\left(\Gamma_{T}\left(X_{1}\right)\right)+\sigma_{\langle y\rangle}^{\#}\left(\Gamma_{T}\left(X_{2}\right)\right) \geq \sigma^{\#}\left(\Gamma_{T}\left(X_{1} \cap X_{2}\right)\right)+\sigma_{\langle y\rangle}^{\#}\left(\Gamma_{T}\left(X_{1} \cup X_{2}\right)\right),
$$

which together with the supermodularity of $\varrho^{\#}$, completes the proof.

This statement is more restrictive than the original version, but is sufficient to derive Lemma 4.9. Hence the proof of the main theorem remains valid.

\section{References}

[1] S. Iwata: Principal structure of submodular systems and Hitchcock-type independent flows, Combinatorica, 15 (1995), 515-532.

Satoru Iwata

Research Institute for

Mathematical Sciences,

Kyoto University,

Kyoto, Japan

Mathematics Subject Classification (1991): 05 B 35, 90 C 27 